\title{
Cerebrospinal fluid enolase isoenzymes and neurotoxicity in early treatment of lymphoblastic leukaemia
}

\author{
J A ROYDS, J S LILLEYMAN, W R TIMPERLEY, AND C B TAYLOR \\ Department of Biochemistry, University of Sheffield, Department of Haematology, The Children's Hospital \\ and Department of Neuropathology, Royal Hallamshire Hospital, Sheffield
}

SUMMARY Serial measurements of enolase in the cerebrospinal fluid were made in 19 children with lymphoblastic leukaemia undergoing their first 6 weeks of antineoplastic treatment. The neurone-specific $\gamma$ enolase value rose appreciably in nearly all patients during the first two weeks of treatment, which comprised chemotherapy only, but the mean values for this isoenzyme failed to show any further rise during the subsequent cranial irradiation. In contrast the $\alpha$ enolase value, which is derived predominantly from glial tissue, rose progressively to attain its highest value during radiotherapy. A consideration of the likely rate of clearance of $\gamma$ enolase from the cerebrospinal fluid and the time sequence of administration of the several chemotherapeutic agents in UKALL VIII suggests that asparaginase may be the main causative agent in the rise of this marker of neuronal damage.

Children with lymphoblastic leukaemia (ALL) can sustain damage to the central nervous system (CNS) purely as a result of the disease itself, ${ }^{1}$ as a result of its treatment, ${ }^{2}$ or as a combination of the two. ${ }^{34}$ While treatment induced damage can be predicied when an early second course of cranial radiotherapy is given for CNS relapse, idiosyncratic neurotoxicity is sometimes seen in children without CNS disease who merely receive 'standard' treatment. These toxic manifestations differ widely and include an encephalopathy currently being seen more frequently in the first month of treatment, cerebrovascular accidents, and, less spectacularly, late mild intellectual impairment occasionally associated with intracranial calcification and minor fits.

At present there is no way of predicting which patients will develop extraordinary treatment induced CNS damage. The recent finding that cerebrospinal fluid $\alpha$ and $\gamma$ enolase seem to be very sensitive markers of glial and neuronal damage respectively ${ }^{6}$ suggests that the concentrations of these isoenzymes may provide the basis for an earlier and more useful index of neurotoxicity. We report changes in the concentrations of immunoreactive $\alpha$ and $\gamma$ enolase in the cerebrospinal fluid in a series of patients undergoing remission induction treatment for ALL.

\section{Patients and methods}

Nineteen consecutive cases of untreated children with ALL were studied. None had CNS disease and all were treated according to the Medical Research Council protocol UKALL VIII in which methotrexate was given intrathecally (days $1,15,29,36,41$, and 48). Radiotherapy, $1800 \mathrm{cGy}$ in 10 fractions over two weeks, was started on day 34 in all except four patients-three developed severe neurotoxicity before radiotherapy was due, and irradiation was delayed in the fourth because the child was less than 2 years old. Concurrent systemic treatment consisted of intramuscular asparaginase given over three weeks as 9 doses of $6000 \mathrm{IU} / \mathrm{m}_{2}$ on alternate days starting on day 4 , and daily prednisone from day 1 to day 29 with reduced doses to day 43 . Weekly intravenous vincristine was given from day 1 to day 29; and intravenous daunorubicin on days 1 and 2 (in 11 of 19 cases). Co-trimoxazole and mercaptopurine were given by mouth from day 29 onwards.

Samples of cerebrospinal fluid were obtained from all patients on day 1 before treatment was started and again on day 15 before the third dose of vincristine and the second of intrathecal methotrexate. For all but the four patients noted above, 
who had their radiotherapy postponed, a further sample was taken at 36 days - 48 hours after starting radiotherapy and before the fourth intrathecal methotrexate.

Immunoreactive $\alpha$ and $\gamma$ enolase was determined in cerebrospinal fluid by radioimmunoassay as previously described. ${ }^{6}$ Monospecific antisera were raised in rabbits against the pure human isoenzymes and the proteins were labelled with iodine- 125 by the method of Bolton and Hunter. ${ }^{7}$

\section{Results}

The individual changes in cerebrospinal fluid isoenzyme concentrations between the values before treatment and those found at 15 days are shown in Fig. 1. The mean values for these samples and also for those taken at $\mathbf{3 6}$ days, two days after the start of radiotherapy, are given in Table 1 . The values before treatment $(\alpha$ enolase $5.24 \mathrm{ng} / \mathrm{ml}, \gamma$ enolase $6 \cdot 24 \mathrm{ng} / \mathrm{ml}$ ) cannot be compared directly with those for normal subjects of a similar age range because it is impractical to obtain cerebrospinal fluid samples from healthy children, but over $90 \%$ of these values were below the upper limits of normal that we have previously reported for adults ( $\alpha$ enolase $10.4 \mathrm{ng} / \mathrm{ml}$, $\gamma$ enolase $8.0 \mathrm{ng} / \mathrm{ml}$ ). Changes in isoenzyme concentrations between 15 and 36 days are shown in Fig. 2 .

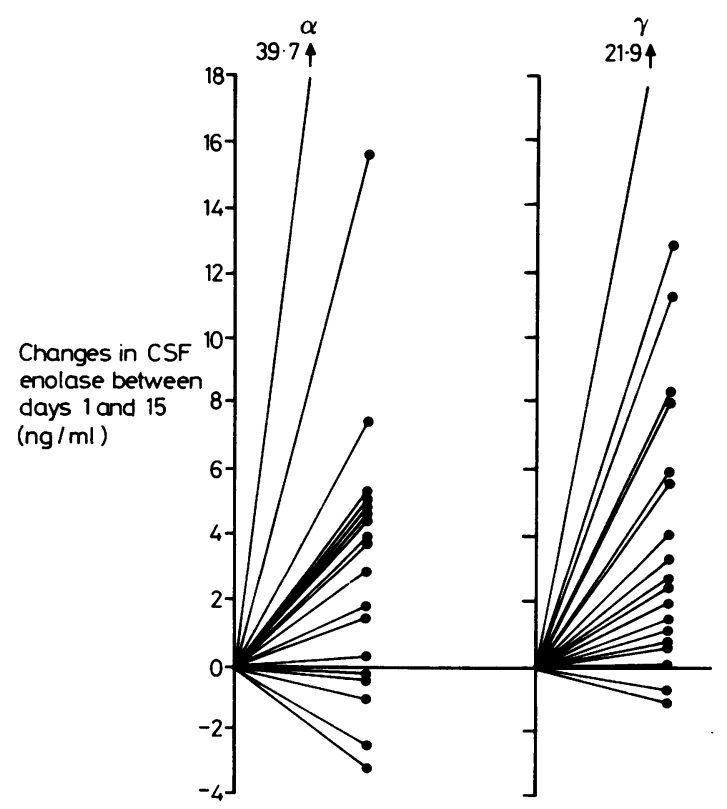

Fig. 1
Table 1 Mean (SEM) concentrations of enolase isoenzymes in cerebrospinal fluid $(\mathrm{ng} / \mathrm{ml})$

\begin{tabular}{llll}
\hline $\begin{array}{l}\text { Enolase } \\
\text { isoenzyme }\end{array}$ & Day 1 & Day 15 & Day 36 \\
\hline$\alpha$ & $5.24(0.73)$ & $10.21(2.23)$ & $13.84(1.86)$ \\
$\gamma$ & $6.24(1.00)$ & $11.1(1.55)$ & $10.86(1.37)$ \\
\hline
\end{tabular}

The mean of the differences of cerebrospinal fluid isoenzyme concentrations found in individual patients between days 1 to 15,15 to 36 , and 1 to 36 are presented in Table 2 , which also shows for each period of comparison the proportion of patients in whom a rise in the isoenzyme occurred.

It can be seen that the concentration of both isoenzymes doubled in the cerebrospinal fluid during the first two weeks of treatment. Three weeks later, two days after the radiotherapy had begun, the raised $\gamma$ enolase value was sustained but there was no overall secondary rise in this isoenzyme. In contrast the $\alpha$ enolase concentration rose again in over $70 \%$ of the patients (Table 2 ), the mean value increasing by $5.5 \mathrm{ng} / \mathrm{ml}$.

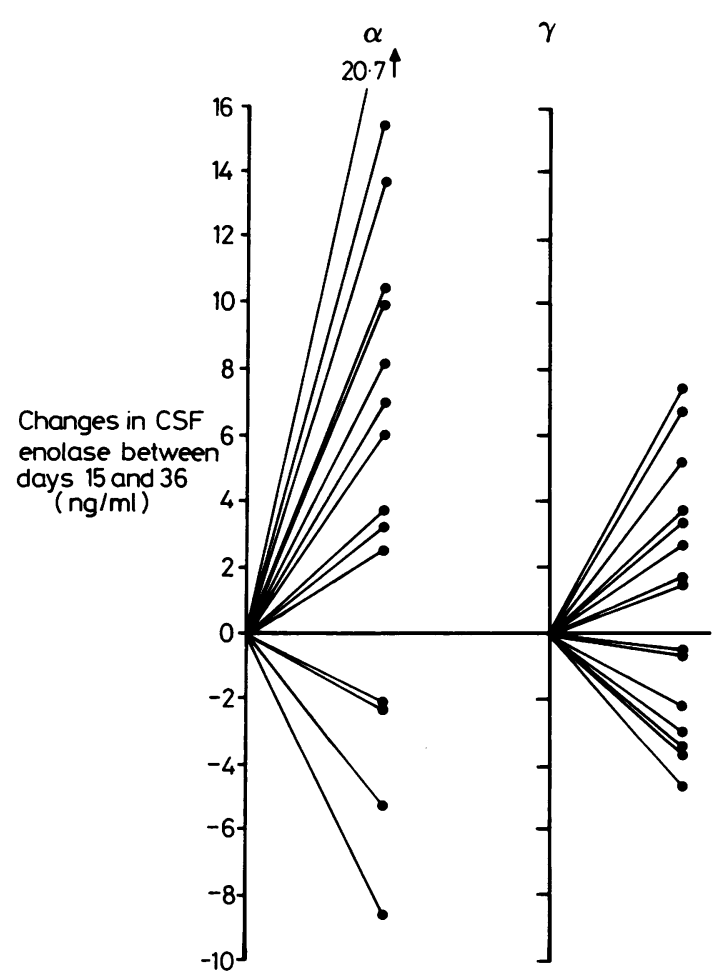

Fig. 2 
Table 2 Mean changes in $\alpha$ and $\gamma$ enolase values over the period of treatment

\begin{tabular}{|c|c|c|c|c|}
\hline $\begin{array}{l}\text { Period of } \\
\text { treatment }\end{array}$ & $\begin{array}{l}\text { Mean change } \\
\text { in } \alpha \text { enolase } \\
\text { values }(\mathrm{ng} / \mathrm{ml})\end{array}$ & $\begin{array}{l}\text { Mean change } \\
\text { in } \gamma \text { enolase } \\
\text { values (ng/ml) }\end{array}$ & $\begin{array}{l}\% \text { cases } \\
\text { with } \alpha \\
\text { enolase } \\
\text { rising }\end{array}$ & $\begin{array}{l}\% \text { cases } \\
\text { with } \gamma \\
\text { enolase } \\
\text { rising }\end{array}$ \\
\hline $\begin{array}{l}\text { Day } 1 \\
\text { to } \\
\text { Day } 15\end{array}$ & $\begin{array}{l}4.98 \\
n=19 \\
P<0.05\end{array}$ & $\begin{array}{l}4.87 \\
n=19 \\
P<0 \cdot 01\end{array}$ & 73.7 & $89 \cdot 5$ \\
\hline $\begin{array}{l}\text { Day } 15 \\
\text { to } \\
\text { Day } 36\end{array}$ & $\begin{array}{l}5.52 \\
n=15 \\
P<0.02\end{array}$ & $\begin{array}{l}0.99 \\
n=15 \\
P<0.05 \text { (NS) }\end{array}$ & $73 \cdot 3$ & $53 \cdot 3$ \\
\hline $\begin{array}{l}\text { Day } 1 \\
\text { to } \\
\text { Day } 36\end{array}$ & $\begin{array}{l}9.66 \\
n=15 \\
P<0.001\end{array}$ & $\begin{array}{l}4.3 \\
n=15 \\
P<0 \cdot 001\end{array}$ & $93 \cdot 3$ & $93 \cdot 3$ \\
\hline
\end{tabular}

The two patients who developed neurotoxicity before radiotherapy had the highest $\gamma$ enolase values in the series $(15.6 \mathrm{ng} / \mathrm{ml}$ and $29.5 \mathrm{ng} / \mathrm{ml})$ at day 15 and in both the rise preceeded the clinical signs of toxicity. The first was a withdrawn three year old girl who gradually became mute and stuporose between day 10 and day 20 , and by day 28 had become cachectic, drowsy, and unresponsive. Her electroencephalograph was grossly abnormal on day 32 with slow low amplitude activity, and computed tomography showed no asymmetry but dilated ventricles and prominent sulci. Her serum aspartatate, glutamate, and ammonia concentrations were all slightly raised at this time (aspartatic acid $32 \mu \mathrm{mol} / 1$ (normal $<25 \mu \mathrm{mol} / \mathrm{l}$ ) glutamic acid and glutamine $886 \mu \mathrm{mol} / \mathrm{l}$ (normal $<750 \mu \mathrm{mol} / \mathrm{l}$ ) ammonia $53 \mu \mathrm{mol} / \mathrm{l}$ (normal $<38 \mu \mathrm{mol} / \mathrm{l}$ )) with no detectable asparagine. After this she gradually but consistently improved from day 50 onwards. At the time of writing (week 52) her behaviour was still abnormal but chiefly consisted of hyperkinesis and an inability to concentrate. She has continued to improve.

The second child was well until day 28 when an unheralded left sided focal seizure progressed to generalised status epilepticus requiring a heminevrin infusion for 6 days for its eventual control. Computed tomography showed no abnormality. A toxic confusional state followed, but she gradually improved over three weeks. At the time of writing (week 30) there was no detectable clinical abnormality, and anticonvulsants had been stopped. In both of these children there was no evidence of concomitant virus or other infection.

The third patient with a major CNS problem, a cerebrovascular accident resulting in a dense right hemiplegia on day 24 in an 8 year old boy, showed a $\gamma$ enolase concentration at 15 days of $6.2 \mathrm{ng} / \mathrm{ml}$, which is within the range of values before treatment, but this rose to $22 \mathrm{ng} / \mathrm{ml}$ shortly after the circulatory incident. At the time of writing (week 53) he had made a full recovery apart from some residual nominal dysphasia and memory problems associated with minor absence seizures controlled with carbamazepine.

\section{Discussion}

There is now good evidence to suggest that damage to glial tissue causes a rise in $\alpha$ enolase in the cerebrospinal fluid, whereas damage to neurones increases $\gamma$ enolase. ${ }^{6}$ The results from the present study indicate that in the first two weeks of treatment on the UKALL VIII schedule, there is damage to both glial cells and neurones in approximately $70 \%$ and $90 \%$ of the patients respectively. The extent of the neural damage, as indicated by the concentrations of $\gamma$ enolase, is clearly very variable but highly significant for the group, and moreover this damage takes place before radiotherapy is begun. Irradiation was associated with a second rise in the concentration of $\alpha$ enolase but the mean value of $\gamma$ enolase was not further raised. The persistence of the raised $\gamma$ enolase concentration presumably indicates sustained damage to the neurones, but the further increase in $\alpha$ enolase suggests that the glial tissue is more sensitive to the radiation than are the neurones.

Since the maximum rise in $\gamma$ enolase occurs between the first and 15th day of treatment (that is, before irradiation), it must be caused by the neurotoxic effects of one or more of the chemotherapeutic components of UKALL VIII. Methotrexate is rapidly cleared from human cerebrospinal fluid ${ }^{8}$ and the same is probably true for $\gamma$ enolase, since a half life of 3.9 hours has been found in rats. ${ }^{9}$ It seems unlikely, therefore, that the raised $\gamma$ enolase value at 15 days was caused by methotrexate, since only a single dose had been given 14 days previously.

During the first 15 days of treatment asparaginase is given 9 times on alternate days. Asparaginase is known to have serious effects upon the liver, pancreas, immune system, and clotting system. ${ }^{5}$ 10 Moreover, from the early days of its use as a selective antineoplastic agent, there have been reports of toxic effects on the CNS. Thus, psychiatric symptoms are found in a substantial proportion of patients ${ }^{11}$ together with lethargy, somnolence, confusion, and abnormal electroencephalograms. ${ }^{12,13}$

Weiss ${ }^{5}$ estimated that 25 to $50 \%$ of patients receiving asparaginase develop ' $\mathrm{L}$-asparaginase encephalopathy', a transient condition occurring early in treatment. A few develop a more serious organic 
brain syndrome at a later stage. Since asparaginase does not penetrate the blood brain barrier ${ }^{5}$ its effects are probably indirect, and the earliest toxic manifestations are possibly caused by excess aspartate, glutamate, and ammonia in the serum; as seen in one of our patients with an encephalopathy (the only one who had these substances assayed). The later effects may be caused by protracted inhibition of protein synthesis after asparagine depletion of the cells of the CNS. The severity of this inhibition would depend upon the extent to which these cells can synthesise their own asparagine. This ability may differ between individuals and could explain some of the variation found in this study in the clinical signs of toxicity and in the isoenzyme values in the cerebrospinal fluid.

The importance of this present study is that it may permit detection of sensitive subjects early enough for changes to be made to the treatment regimen. It is possible that infusion of asparagine would halt the toxic process before irreversible damage has taken place.

The authors thank Miss Pauline Little for her technical assistance and Mrs P Kirk for typing the manuscript. Financial support from the Wellcome Trust (Grant No. 11353/1.5) and from the Special Trustees for the Former United Sheffied Hospitals (Grant No. 276) is gratefully acknowledged.

\section{References}

${ }^{1}$ Pochedly C. Leukaemia and lymphoma in the nervous system. Springfield, USA: Charles C Thomas, 1977.

2 Price RA, Jamieson PA. The central nervous system in childhood leukaemia. II Subacute leukoencephalopathy. Cancer 1975;35:306-18.
3 Oliff A, Bleyer WA, Poplack DG. Acute encephalopathy after initiation of cranial irradiation for meningeal leukaemia. Lancet 1978;ii:13-5.

4 Kay HEM, Knapton PJ, O'Sullivan JP, et al. Encephalopathy in acute leukaemia associated with methotrexate therapy. Arch Dis Child 1972;47:344-54.

5 Weiss HD, Walker MD, Wiernik PH. Neurotoxicity of commonly used antineoplastic agents Part I. $N$ Engl $J$ Med 1974;291:75-81.

6 Royds JA, Davies-Jones GA, Lewtas NA, Timperley WR, Taylor CB. Enolase isoenzymes in the cerebrospinal fluid of patients with diseases of the nervous system. J Neurol Neurosurg Psychiatry 1983;46:1031-6.

7 Bolton AE, Hunter WM. The labelling of proteins to high specific radioactivities by conjugation to a ${ }^{125}$ I-containing acylating agent. Biochem $J$ 1973;133:529-39.

${ }^{8}$ Bode U, Magrath IT, Bleyer WA, Poplack DG, Glaubiger DL. Active transport of methotrexate from cerebrospinal fluid in humans. Cancer Res 1980;40:2184-87.

9 Scarna H, Delafosse B, Steinberg R, Debilly G, Mandrand B, Keller A, Pujol JF. Neuronspecific enolase as a marker of neuronal lesions during various comas in man. Neurochemistry International 1982;4:405-11.

10 Haskell CM. L-asparaginase: human toxicology and single agent activity in nonleukemic neoplasms. Cancer Treat Rep 1981;65(Suppl 4):57-9.

${ }^{11}$ Holland J, Fasanello S, Ohnuma T. Psychiatric symptoms associated with $\mathrm{L}$-asparaginase administration. $J$ Psychiatr Res 1974;10:105-13.

12 Land VJ, Sutow WW, Fernbach DJ, Lane DM, Williams TE. Toxicity of L-asparaginase in children with advanced leukemia. Cancer 1972;30:339-47.

${ }^{13}$ Moure JMB, Whitecar JP, Jr, Bodey GP. Electroencephalogram changes secondary to asparaginase. Arch Neurol 1970;23:365-8.

Correspondence to $\mathrm{Dr} J \mathrm{~S}$ Lilleyman, The Department of Haematology, The Children's Hospital, Western Bank, Sheffield S10 2TH.

Received 28 November 1983 